\title{
Age Effect on Retina and Optic Disc Normal Values
}

\author{
Aljoscha S. Neubauer ${ }^{a}$ Christos Chryssafis $^{a}$ Martin Thiel $^{a}$ \\ loannis Tsinopoulos ${ }^{b}$ Christoph Hirneiss $^{a} \quad$ Anselm Kampik $^{a}$ \\ ${ }^{a}$ Department of Ophthalmology, Ludwig Maximilians University, Munich, Germany; \\ ${ }^{b}$ Department of Ophthalmology, Aristoteles University of Thessaloniki, Thessaloniki, Greece
}

\section{Key Words}

Glaucoma $\cdot$ Retinal thickness · Optic disc ·

Normal data $\cdot$ Age effect

\begin{abstract}
Purpose: To investigate retinal thickness and optic disc parameters by the Retinal Thickness Analyzer (RTA) glaucoma program in older normal subjects and to determine any age effect. Methods: Subjects over 40 years of age without any prior history of eye diseases were recruited. Only subjects completely normal on clinical ophthalmologic examination and on visual field testing by Humphrey Field Analyzer (HFA) using the SITA 24-2 program were included. A total of 74 eyes from 74 subjects with even age distribution over the decades were enrolled and underwent topographic measurements of the posterior pole and of the optic disc by RTA. The 'glaucoma full' program in software version 4.11B was applied. Results: Mean patient age was $59.9 \pm 10.3$ years with a range from 40 to 80 years. The only parameter intraocular pressure (IOP) correlated with was retinal posterior pole asymmetry $(r=0.27, p=0.02)$. IOP itself increased significantly with age $(r=0.341, p=0.003)$.
\end{abstract}

Presented in part at the 16th annual meeting of the International Perimetric Society (IPS) 2004 in Barcelona, Spain.
(C) 2005 S. Karger AG, Basel 0030-3747/05/0375-0243\$22.00/0

Fax +4161306 1234 E-Mail karger@karger.ch www.karger.com www.karger.com/ore
Mean defect and pattern standard deviation of the HFA did not correlate with any of the retinal or optic disc measurements. Increasing age correlated significantly with some of the morphologic measurements of the RTA: decreasing perifoveal minimum thickness $(r=-0.258, p=$ $0.026)$, increased cup-to-disc area ratio $(r=0.302, p=$ $0.016)$ and increased cup area $(r=0.338 p=0.007)$. Conclusions: An age effect exists for some of the retina and optic disc measurements obtained by the RTA.

Copyright (C) 2005 S. Karger AG, Basel

\section{Introduction}

Visual loss in chronic glaucoma results from a destruction of retinal ganglion cells. However, visual field loss occurs relatively late in the progression of this disease [1]. Estimations suggest that at least $25-35 \%$ of the ganglion cells must be lost prior to the development of a visual field abnormality detectable with modern automated threshold testing $[1,2]$. As a result there is still considerable interest in developing more sensitive and more reliable methods for making an earlier diagnosis in glaucoma. On the other hand it is well known that certain changes of the optic disc may be more sensitive for glaucoma diagnosis than white-on-white visual fields [3]. However, correctly identifying and assessing these changes needs considerable experience. Therefore in the last years several new

Christos Chryssafis, MD

Department of Ophthalmology, Ludwig Maximilians University

Mathildenstrasse 8, DE-80336 München (Germany)

Tel. +49 8951603811, Fax +49 8951605160

E-Mail aljoscha.neubauer@med.uni-muenchen.de 
imaging methods have become available for exactly quantifying changes of the optic disc over time. They include the Heidelberg Retina Tomograph (HRT) and Optical Coherence Tomography (OCT) and may offer advantages for early glaucoma diagnosis [4].

Recently, the Retinal Thickness Analyzer (RTA, Talia Technology, Neve-Ilan, Israel) has been adapted to also measure the optic disc. This machine has been applied to diagnose retinal changes for several years focusing on retinal maps [5]. Its ability to measure retinal thickness might also be useful in diagnosing early glaucomatous changes $[6,7]$. In the current version of this machine a special program for glaucoma diagnostics is implemented combining retinal map and optic disc measurements obtained from three-dimensional analysis. As the optic nerve head is known to undergo changes [8] probably due to normal ganglion cell loss with age [9], the aim of the current study was to investigate the normal values for the RTA glaucoma program and to determine any age effect.

\section{Methods}

\section{Subjects}

Consecutive normal subjects were recruited without any history of glaucoma, diabetes mellitus, or any other disease that might influence retinal thickness. Additionally no family history of glaucoma in a first-degree relative, no systemic medication that might influence retinal thickness, no history of ocular trauma, intraocular surgery or laser treatment were allowed. All subjects had to be more than 40 years of age. Subjects were excluded for refractive errors $>+6$ or $<-6$ diopters of spherical equivalent, full corrected visual acuity worse than 20/40, intraocular pressure (IOP) measured by applanation tonometry $>21 \mathrm{~mm} \mathrm{Hg}$, any significant lens opacity or any other significant media opacities as well as for any posterior segment abnormality as defined by clinical biomicroscopic exam. The appearance of the optic disc was not part of the inclusion or exclusion criteria.

All subjects were examined after proper written consent and approval of the local ethics board at the Department of Ophthalmology, Ludwig Maximilians University, Munich. All research was conducted in accordance with institutional guidelines and conformed to the tenets of the World Medical Association Declaration of Helsinki. An ophthalmological examination including refraction, full-corrected visual acuity, biomicroscopic evaluation of the anterior segment and applanation IOP measurement as well as an initial evaluation of the posterior pole through an undilated pupil was performed by one experienced examiner (C.C.). Then the visual field of one randomly chosen eye was tested (see below). After pupil dilation with $1 \%$ tropicamide stereoscopic biomicroscopy of the posterior segment was performed. Finally RTA scanning of the posterior pole and of the optic disc were carried out as described in detail below.
Visual Fields

Swedish Interactive Threshold Algorithm (SITA) 24-2 visual field testing was applied on a Humphrey Field Analyzer (HFA, Humphrey-Zeiss Instruments Ltd., San Leandro, Calif., USA). Subjects were required to have reliable, normal visual fields. A reliable visual field test was defined as having fewer than 30\% fixation losses, false positive and false negative responses. A normal visual field was defined as having no cluster of three or more adjacent points depressed more than $5 \mathrm{~dB}$ or two adjacent points depressed more than $10 \mathrm{~dB}$. Repeating visual fields once was admitted. If the repeated visual field still showed abnormalities, the subject was excluded from the study.

\section{RTA Measurements}

A commercially available RTA (Talia Technology, Neve-Ilan, Israel) was used for measurements. The RTA is capable of providing retinal thickness maps and stereoscopic measurements for the optic disc. The principles of measurement have been described in detail elsewhere $[10,11]$. Input of the corneal curvature is used to correct for different amounts of ametropia. Depth resolution for retinal thickness measurements is known to be in the range of 20$50 \mu \mathrm{m}[12]$. The software version applied was 4.11B. For the current study, posterior pole thickness maps were obtained and analyzed automatically by the glaucoma full program. Subjects were excluded, if the RTA measurements could not be obtained for both optic disc and retina or measurements yielded any error messages from the instrument such as more than 4 adjacent points marked to be unreliable in the retina map or any missing values or warnings in the RTA analysis printouts. This meant also excluding all subjects with any significant changes in the retinal thickness as compared to the instrument's normative database. Such changes might for example occur in preperimetric glaucoma [7].

Measurements obtained for the posterior pole were posterior pole minimum thickness, perifoveal minimum thickness, posterior pole (superior/inferior) asymmetry, perifoveal (superior/inferior) asymmetry, abnormally thin posterior pole area, abnormally thin perifoveal area, the number of posterior pole thin clusters and corrected posterior pole pattern deviation. Here, the 'fovea' was defined as a circle $1.6 \mathrm{~mm}$ in diameter centered on the foveal depression. The term 'perifoveal' describes a circle $5 \mathrm{~mm}$ in diameter centered on the foveal depression excluding the previously defined 'fovea'. 'Posterior pole' defines a $6 \times 6 \mathrm{~mm}$ area (approximately $21 \times 21$ ) centered on the fovea. The asymmetry (superior/inferior) of the posterior pole describes the normalized ratio (in \%) of the mean of all retinal thickness measurements of the superior to that of the inferior half of the posterior pole. Thus a value of zero would indicate an identical mean of all superior and inferior thickness measurements. Perifoveal asymmetry (superior/inferior) is defined in analogy with the perifoveal area. 'Abnormally thin areas' are defined as the percentage of areas 2 or more standard deviations (SD) below the internal normative values of the RTA. A 'cluster' means 4 or more adjacent data points, i.e. measurements, each of which is at least $2 \mathrm{SD}$ below the normative values. The corrected posterior pole pattern deviation gives the overall deviation of all retinal thickness measures for the current patient as compared to the internal normative database of the RTA.

The RTA's automated analysis of the optic disc yields twelve stereometric parameters of the optic nerve head (table 2). The disc area is defined by the total area of the optic disc, which is delineated by the user. In the current study this contour line was encir- 
Table 1. RTA measurements for the retinal posterior pole

\begin{tabular}{lllllllll}
\hline Statistical analysis & $\begin{array}{l}\text { Posterior } \\
\text { pole minimum } \\
\text { thickness, } \mu \mathrm{m}\end{array}$ & $\begin{array}{l}\text { Perifoveal } \\
\text { minimum } \\
\text { thickness, } \mu \mathrm{m}\end{array}$ & $\begin{array}{l}\text { Posterior pole } \\
\text { (superior/inferior) } \\
\text { asymmetry, \% }\end{array}$ & $\begin{array}{l}\text { Perifoveal } \\
\text { (superior/inferior) } \\
\text { asymmetry, \% }\end{array}$ & $\begin{array}{l}\text { Posterior } \\
\text { pole abnormally } \\
\text { thin area, \% }\end{array}$ & $\begin{array}{l}\text { Perifoveal } \\
\text { abnormally } \\
\text { thin area, \% }\end{array}$ & $\begin{array}{l}\text { Posterior } \\
\text { pole number } \\
\text { of thin clusters }\end{array}$ & $\begin{array}{l}\text { Posterior } \\
\text { pole pattern } \\
\text { deviation, } \mu \mathrm{m}\end{array}$ \\
\hline Mean & 116.82 & 131.43 & -3.39 & -2.72 & 1.32 & 1.61 & 0.30 & 17.43 \\
SD $( \pm)$ & 18.76 & 22.86 & 7.28 & 7.01 & 3.39 & 4.20 & 0.57 & 6.19 \\
Range & $82-162$ & $82-205$ & $-24.14-13.8$ & $-21.75-11.61$ & $0-19.72$ & $0-25.22$ & $0-2$ & $7.23-39.8$ \\
$2.5-97.5 \%$ percentile & $83-161$ & $88-179$ & $-20.50-9.81$ & $-19.47-10.53$ & $0-14.42$ & $0-18.64$ & $0-2$ & $8.46-38.84$ \\
\hline
\end{tabular}

Normal measurements for the posterior pole obtained by RTA. For a detailed description of the measurements please refer to the 'Methods' section.

cled manually in free-hand mode by one experienced examiner (C.C.). The reference plane was derived automatically by determining the average height of the contour line in the temporal lower quadrant (in a sector between $4^{\circ}$ and $10^{\circ}$ from the horizontal) and subtracting $50 \mu \mathrm{m}$ from the contour line [13]. The cup area gives the excavation of the disc within the contour line and below this reference plane, the rim area is defined above this plane. The cup/ disc area ratio gives the ratio of the cup and disc area as a coefficient. The cup and rim volumes are defined analogous to the corresponding areas. Mean cup depth defines the mean of all depths within the cup, the maximum cup depth describes their maximum. The cup shape measure gives the slope of the cup: negative values describe a shallow, positive values represent a steep slope. The height variation of the contour line gives the distance in millimeters between the highest and the lowest point on the contour line, thus indicating the irregularity of the disc margin. Mean retinal nerve fiber layer (RNFL) thickness is calculated by the mean in millimeters of the retinal surface along the contour line and above the reference plane. The RNFL cross section area is calculated by this mean RNFL thickness multiplied by the length of the contour line.

\section{Statistics}

Data were collected in an MS-Excel 2000 spreadsheet (Microsoft Corp., Unterschleissheim, Germany) and analyzed using SPSS 11.5 for Windows (SPSS Inc., Chicago, Ill., USA). In all statistical tests $\mathrm{p}<0.05$ was considered significant. For the normative values the mean values, minimum, maximum, standard deviation as well as the 2.5 and $97.5 \%$ percentiles are listed. Spearman correlation as well as graphical analysis were performed to investigate any correlations. Further analysis such as regression models or analysis of variance (ANOVA) were performed where appropriate.

\section{Results}

\section{Subjects}

A total of 106 subjects ( 77 female and 29 male) met the inclusion criteria and were examined. In 10 subjects the RTA yielded error warnings/messages in the analysis and those subjects were excluded. Further 10 subjects were excluded manually due to suboptimal RTA scans for reasons such as inadequate slit illumination or focus as defined by consensus of 2 observers (C.C. and A.S.N.). Two of those subjects also had visual field abnormalities. A total of 12 subjects were excluded due to visual field abnormalities alone. This finally left 74 (53 female and 21 male) subjects meeting all inclusion and exclusion criteria. Their mean \pm standard deviation (SD) age was 59.9 \pm 10.3 years (range $40-80$ years). A total of 15 subjects (20\%) were within 40-49 years, 17 (23\%) within 50-59 years, 28 (38\%) within 60-69 years, and $14(19 \%)$ within $70-80$ years. In total 44 right eyes and 30 left eyes were examined (no significant difference, $p=0.1$ ). Mean visual acuity was 20/22 (i.e. for decimal visual acuity in $\log$ steps: $0.91 \pm 0.42$, range $0.5-1.0$ ). Mean IOP was 15.2 $\pm 1.8 \mathrm{~mm} \mathrm{Hg}$ (range 12-20 mm Hg), mean spherical equivalent $+0.53 \pm 1.38 \mathrm{dpt}$ (range -4.0 to +5.0 ). A total of 18 subjects had a myopic, 50 a hyperopic and 6 a plano-refraction. For visual fields the mean deviation (MD) was $-1.07 \pm 1.23 \mathrm{~dB}$ (range -4.3 to +3.0 ), the pattern standard deviation (PSD) was mean $1.89 \pm 0.63$ (range 1.0-4.7).

\section{Normative Values for the Retina}

In table 1 the normative values for the retina as obtained by RTA glaucoma full program are given. Please note that for retinal thickness the minimal values and not the mean thickness are calculated by the RTA glaucoma program. Remarkably for the superior/inferior asymmetry a negative value is obtained, which means that the inferior retina tends to be on average 3\% thicker than the superior retina. No differences between right and left eyes were observed on ANOVA. 
Table 2. RTA measurements for the optic disc

\begin{tabular}{|c|c|c|c|c|c|c|c|c|c|c|c|c|}
\hline $\begin{array}{l}\text { Statistical } \\
\text { analysis }\end{array}$ & $\begin{array}{l}\text { Disc area } \\
\mathrm{mm}^{2}\end{array}$ & $\begin{array}{l}\text { Cup area } \\
\mathrm{mm}^{2}\end{array}$ & $\begin{array}{l}\text { Cup/ } \\
\text { disc area } \\
\text { ratio }\end{array}$ & $\begin{array}{l}\text { Rim } \\
\text { area } \\
\mathrm{mm}^{2}\end{array}$ & $\begin{array}{l}\text { Cup } \\
\text { volume } \\
\mathrm{mm}^{3}\end{array}$ & $\begin{array}{l}\text { Rim } \\
\text { volume } \\
\mathrm{mm}^{3}\end{array}$ & $\begin{array}{l}\text { Mean cup } \\
\text { depth } \\
\text { mm }\end{array}$ & $\begin{array}{l}\text { Maximum } \\
\text { cup depth } \\
\mathrm{mm}\end{array}$ & $\begin{array}{l}\text { Cup shape } \\
\text { measure }\end{array}$ & $\begin{array}{l}\text { Height varia- } \\
\text { tion of the con- } \\
\text { tour- line, mm }\end{array}$ & $\begin{array}{l}\text { Mean RNFL } \\
\text { thickness } \\
\mathrm{mm}\end{array}$ & $\begin{array}{l}\text { RNFL cross } \\
\text { section area } \\
\mathrm{mm}^{2}\end{array}$ \\
\hline Mean & 2.92 & 0.89 & 0.3 & 2.04 & 0.2 & 0.44 & 0.18 & 0.55 & -0.18 & 0.34 & 0.2 & 1.18 \\
\hline $\mathrm{SD}( \pm)$ & 0.55 & 0.58 & 0.18 & 0.86 & 0.18 & 0.25 & 0.09 & 0.22 & 0.07 & 0.1 & 0.09 & 0.44 \\
\hline $\begin{array}{l}\text { Range } \\
2.5-97.5 \%\end{array}$ & $1.27-4.49$ & $0.06-2.04$ & $0.02-0.65$ & $1.10-3.35$ & $0.00-0.83$ & $0.10-1.16$ & $0.02-0.50$ & $0.07-1.13$ & $-0.34-0.02$ & $0.17-0.65$ & $0.05-0.41$ & $0.28-2.76$ \\
\hline percentile & $1.79-4.29$ & $0.07-2.02$ & $0.03-0.63$ & $1.12-3.34$ & $0-0.78$ & $0.11-1.04$ & $0.05-0.40$ & $0.13-0.98$ & $-0.33-0.02$ & $0.17-0.61$ & $0.05-0.40$ & $0.37-2.36$ \\
\hline
\end{tabular}

Normal measurements for the optic disc obtained by RTA. For a detailed description of the measurements please refer to the 'Methods' section.

\section{Normative Values for the Optic Disc}

In table 2 the normative values for the optic disc as obtained by RTA glaucoma full program with dilated pupils are given. When correlating the data for the optic disc with those for retinal thickness significant correlations existed in the normal subjects analyzed only for the RNFL cross section area of the optic disc with minimal thickness of the posterior pole $(r=0.311, p=0.013)$ and for RNFL area with perifoveal minimal thickness $(r=0.295, p=$ 0.019). This means that the smaller the optic disc RNFL area the thinner the central retinal thickness. All other parameters of the optic disc were uncorrelated to the retina parameters. By ANOVA all parameters were investigated for differences between left and right eyes. Only one parameter showed a significant difference: left eyes had a larger rim area $\left(2.22 \pm 0.49 \mathrm{~mm}^{2}\right)$ as compared to right eyes $\left(1.92 \pm 0.48 \mathrm{~mm}^{2} ; \mathrm{p}=0.021\right)$.

\section{Correlation with Visual Fields}

Mean defect and pattern standard deviation of the HFA did not correlate with any of the RTA's retinal or optic disc measurements. Increasing age did not influence the analyzed HFA parameters MD and PSD, which are age-corrected by the instrument.

\section{Correlation with Clinical Data}

When comparing the RTA measurements with the available clinical data, i.e. visual acuity, IOP and refraction, some correlations were found. Refraction (in spherical equivalent) correlated significantly with rim area $(r=$ $-0.293, p=0.020)$, rim volume $(r=-0.324, p=0.010)$ and mean RNFL thickness $(r=-0.251, p=0.031)$. This means in accordance with previous studies [14] the more hyperopic the subject, the smaller the RNFL- and rim-associated measurements. To exclude the theoretical possibility that age- or IOP-associated changes interfere, those two factors together with refraction were entered in a multiple, stepwise regression model predicting rim area, rim volume and mean RNFL thickness. For all those models the factors age and IOP were excluded as not significant.

Interestingly, IOP correlated only with one measurement significantly, the superior/inferior asymmetry of the posterior pole $(r=0.273, p=0.019)$. This relationship is shown in figure 1. IOP did not correlate with any of the optic disc measurements in this perimetrically normal collective. Asymmetry of the perifoveal area gave similar results not statistically significant $(r=0.226, p=0.053)$.

\section{Effect of Age}

Age had an effect on several clinical as well as morphometric measures. On RTA, age correlated significantly $(\mathrm{r}=-0.258, \mathrm{p}=0.026)$ with perifoveal minimal thickness (fig. 2a), with cup area $(r=0.338 \mathrm{p}=0.007)$ and cup-todisc area ratio $(r=0.302, p=0.016$; fig. $2 b)$. This means that older subjects tend to have a lower minimum retinal thickness, larger cups and a larger cup-to-disc area ratio. All other parameters were not affected by age. Particularly, no age effect at all was observed for the superior/inferior asymmetry of the posterior pole $(r=0.064, p=$ 0.586 ), which has been shown in figure 1 to correlate with IOP. This is remarkable as IOP itself showed some increase with age $(r=0.341, p=0.003$; fig. $2 c)$. The superior/inferior asymmetry was further investigated in a multiple stepwise regression model including the theoretical predictors age, IOP and refraction. The only significant predictor found was IOP $(p=0.018)$ with a standardized beta of 0.275 , which illustrates the independence of superior/inferior asymmetry from the other two factors. Refraction showed a shift towards hyperopia ( $\mathrm{r}=$ $0.305, \mathrm{p}=0.008)$ with age and best corrected visual acuity tended to be lower with increasing age $(r=-0.328$, $\mathrm{p}=0.015)$ in the examined normal subjects. 


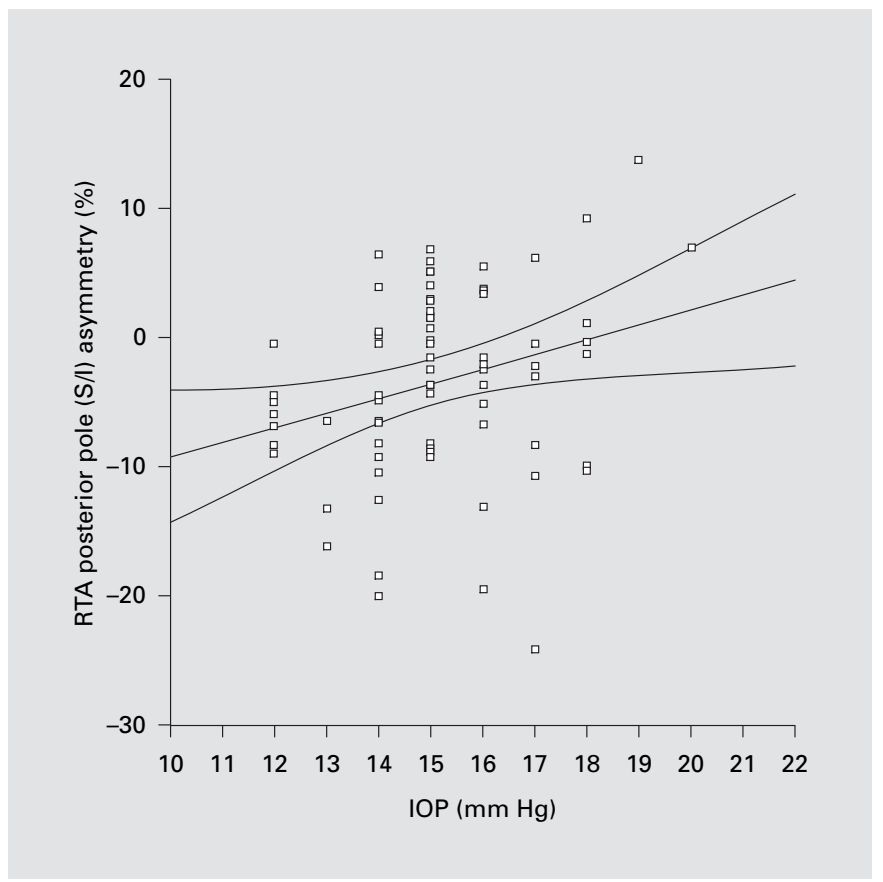

Fig. 1. Correlation of IOP with superior/inferior (S/I) asymmetry of the posterior pole measured by RTA. Negative values mean that the inferior retina tends to be on average 3\% thicker than the superior retina. A correlation $(\mathrm{r}=0.273, \mathrm{p}=0.019)$ is obtained in this perimetrically normal older subjects: a higher IOP is associated with a higher superior/inferior asymmetry. The line in the graph gives the linear regression line, the curves indicate the $95 \%$ confidence intervals for the regression line.

Fig. 2. Aging effects. In all plots the single measurements as well as the linear regression line and 95\% confidence intervals for the regression (curved lines) are given. With increasing age of the normal subjects a significant reduction of perifoveal minimal thickness $(\mathrm{r}=-0.258, \mathrm{p}=0.026)$ is observed; the other retinal parameters do not change significantly. Cup-to-disc area ratio $(\mathrm{r}=0.302, \mathrm{p}=$ $0.016)$ as well as cup area $(r=0.338 \mathrm{p}=0.007$, not plotted $)$ as measured by RTA increase significantly with age. IOP increases significantly with age $(\mathrm{r}=0.341, \mathrm{p}=0.003)$ in the sample of normal subjects examined.
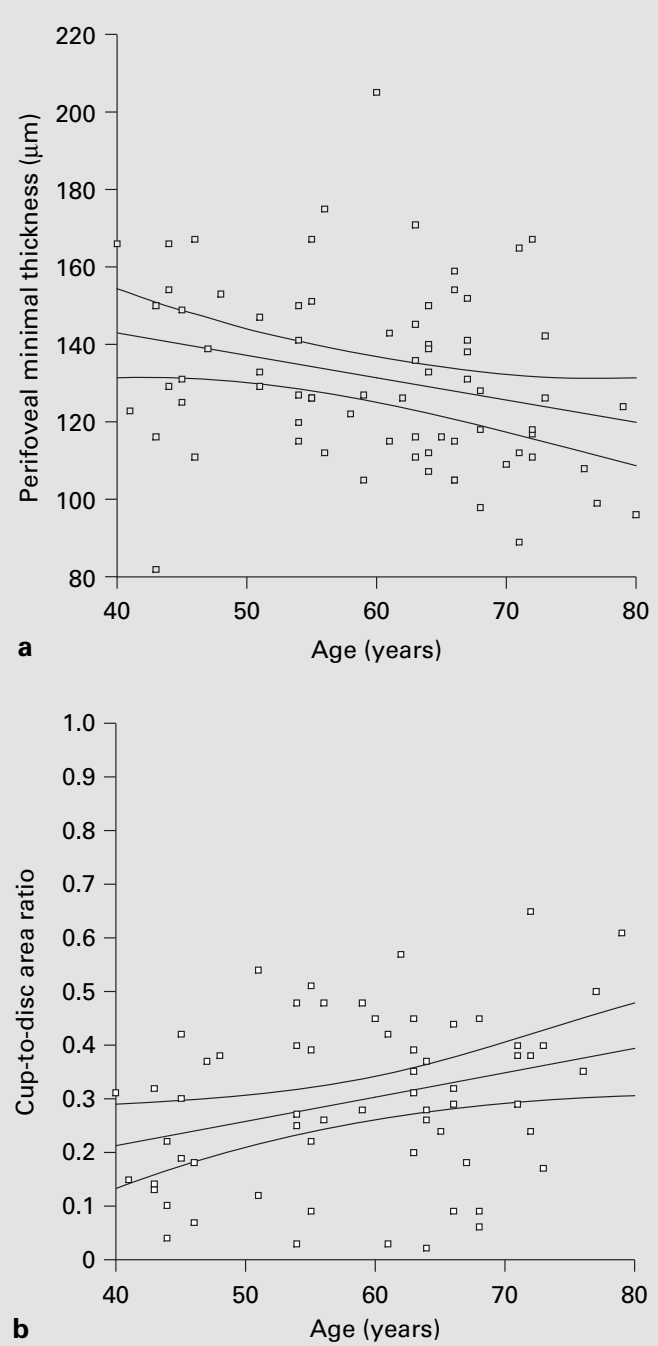

b

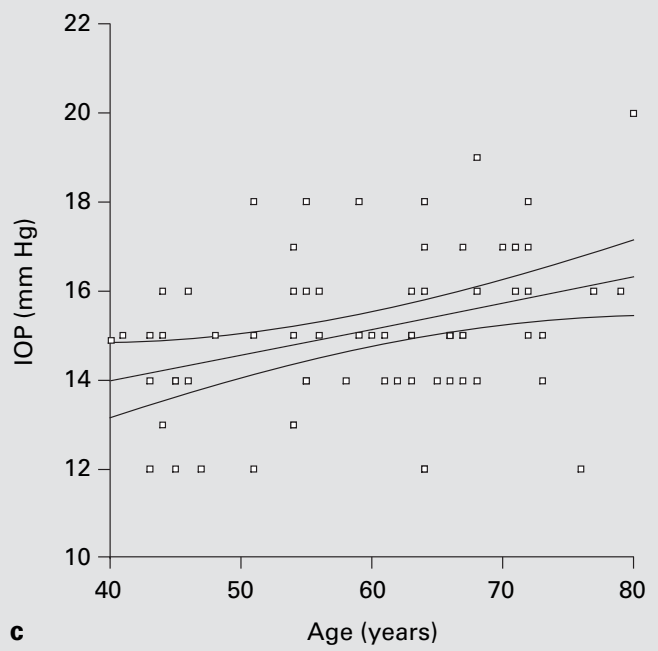




\section{Discussion}

In the current study we present measurements for the retina and optic disc obtained by RTA in a well-characterized, perimetrically normal collective of older individuals. We could prove some known effects of aging by RTA measurements such as decreasing retinal thickness and increasing cup and cup-to-disc ratio of the optic nerve head. Additionally an unsuspected effect of IOP on retinal thickness asymmetry was found, which might suggest some value of such markers for glaucoma diagnostics [15, $16]$.

It is difficult to compare the normative values obtained with the RTA glaucoma program for the retina with the results from other studies, as minimal retinal thickness and asymmetry indices are generated instead of absolute thickness measurements. However, it is well known that RTA thickness measurements of the retina tend to be lower than OCT measurements [12, 17]. The details of OCT, which measures distances based on optical interferometry of an optical coherent light source, have been described elsewhere [18, 19]. For the minimal retinal thickness in earlier studies Emi et al. [20] found by ultrasound and Fourier analysis $112 \mu \mathrm{m}$, which correlates very well with our results. This is also consistent with manually determining the minimum foveal thickness by OCT, which gives approximately $150 \mu \mathrm{m}[12,21]$. When considering that OCT measurements tend to be approximately 30-40 $\mu \mathrm{m}$ higher than RTA measurements [12, 22], this yields similar values to the $117 \mu \mathrm{m}$ obtained in our current study.

The validity of optic disc measurements by RTA has previously been shown [13] and its repeatability [23] is known to be similar to that of confocal scanning microscopy with the HRT $[24,25]$. However, all absolute measurements of the RTA differ from those obtained by HRT, which is obvious for the optic disc size. Much higher values are obtained (mean $2.92 \mathrm{~mm}^{2}$ ) as compared to HRT, which has a mean disc size of $1.81 \mathrm{~mm}^{2}$ [26]. However, this does not question the accuracy of RTA measurements as it is well known that HRT measurements underestimate the size compared to photographic methods $[27,28]$. The photographically determined mean disc area has been described by Jonas et al. [29] to be $2.69 \pm$ $0.70 \mathrm{~mm}^{2}$ in a large number of patients, which is only slightly lower than the data measured by RTA in our study. A discrepancy between RTA and HRT data is also in accordance with other studies directly comparing disc measurements by both instruments [13]. In contrast, for RTA's relative disc parameters such as cup-to-disc area ratio, cup shape or height variation contour a good correlation exists to the data published for the $\operatorname{HRT}[30,31]$. Similarly to previous studies using HRT [32] and laser polarimetry [33] a small but significant difference was found for one out of RTA's twelve optic disc parameters between right and left eyes: the neuroretinal rim of left eyes was larger than that of right eyes. If such difference, which has also been found with the HRT in the opposite direction [34], has any clinical relevance is controversial.

Age was observed in this study to correlate with several morphometric changes such as disc cupping, which has been described previously [8]. With age also an increased IOP and to some extent a decreased perifoveal retinal thickness was measured. These age-related morphometric changes may support the hypothesis of some ganglion cell loss with age [9]. Surprisingly, - independently of age and visual fields - some correlation of IOP was observed on one of the retinal thickness measurements, the superior-to-inferior retinal thickness asymmetry. No other disc or retinal measure correlated with IOP in the examined normal subjects of our study. One might therefore speculate from this finding that higher (but normal) IOPs might cause increased asymmetric, inferior RNFL loss in perimetrically normal subjects. This theory is in accordance with several studies investigating the posterior pole instead of the optic disc for early detection of glaucoma with instruments such as the RTA $[6,35]$ or OCT $[36,37]$, a topic on which further research is needed. In conclusion, we could show in the current study that an age effect exists for some of the retinal and optic disc measurements obtained by RTA, which is consistent with known morphologic changes induced by aging.

\section{Acknowledgment}

The authors thank Mrs. N. Ehsani for expert technical assistance with the RTA. 


\section{References}

1 Harwerth RS, Carter-Dawson L, Shen F, Smith EL 3rd, Crawford ML: Ganglion cell losses underlying visual field defects from experimental glaucoma. Invest Ophthalmol Vis Sci 1999;40: 2242-2250.

2 Kerrigan-Baumrind LA, Quigley HA, Pease ME, Kerrigan DF, Mitchell RS: Number of ganglion cells in glaucoma eyes compared with threshold visual field tests in the same persons. Invest Ophthalmol Vis Sci 2000;41:741-748.

3 Jonas JB, Bergua A, Schmitz-Valckenberg P, Papastathopoulos KI, Budde WM: Ranking of optic disc variables for detection of glaucomatous optic nerve damage. Invest Ophthalmol Vis Sci 2000;41:1764-1773.

4 Girkin CA: Relationship between structure of optic nerve/nerve fiber layer and functional measurements in glaucoma. Curr Opin Ophthalmol 2004;15:96-101.

5 Pires I, Bernardes RC, Lobo CL, Soares MA, Cunha-Vaz JG: Retinal thickness in eyes with mild nonproliferative retinopathy in patients with type 2 diabetes mellitus: comparison of measurements obtained by retinal thickness analysis and optical coherence tomography. Arch Ophthalmol 2002;120:1301-1306.

6 Asrani S, Challa P, Herndon L, Lee P, Stinnett $\mathrm{S}$, Allingham RR: Correlation among retinal thickness, optic disc, and visual field in glaucoma patients and suspects: a pilot study. J Glaucoma 2003;12:119-128.

7 Tanito M, Itai N, Ohira A, Chihara E: Reduction of posterior pole retinal thickness in glaucoma detected using the Retinal Thickness Analyzer. Ophthalmology 2004;111:265-275.

8 Garway-Heath DF, Wollstein G, Hitchings RA: Aging changes of the optic nerve head in relation to open angle glaucoma. Br J Ophthalmol 1997;81:840-845.

9 Harman A, Abrahams B, Moore S, Hoskins R: Neuronal density in the human retinal ganglion cell layer from 16-77 years. Anat Rec 2000; 260:124-131.

10 Zeimer R, Shahidi M, Mori M, Zou S, Asrani $\mathrm{S}$ : A new method for rapid mapping of the retinal thickness at the posterior pole. Invest Ophthalmol Vis Sci 1996;37:1994-2001.

11 Zeimer RC, Mori MT, Khoobehi B: Feasibility test of a new method to measure retinal thickness noninvasively. Invest Ophthalmol Vis Sci 1989;30:2099-2105.

12 Neubauer AS, Priglinger S, Ullrich S, Bechmann M, Thiel MJ, Ulbig MW, Kampik A: Comparison of foveal thickness measured with the retinal thickness analyzer and optical coherence tomography. Retina 2001;21:596601.

13 Itai N, Tanito M, Chihara E: Comparison of optic disc topography measured by retinal thickness analyzer with measurement by Heidelberg Retina Tomograph II. Jpn J Ophthalmol 2003;47:214-220.
14 Rudnicka AR, Frost C, Owen CG, Edgar DF: Nonlinear behavior of certain optic nerve head parameters and their determinants in normal subjects. Ophthalmology 2001;108:23582368.

15 Bozkurt B, Irkec M, Karaagaoglu E, Orhan M: Scanning laser polarimetric analysis of retinal nerve fiber layer thickness in Turkish patients with glaucoma and ocular hypertension. Eur $\mathrm{J}$ Ophthalmol 2002;12:406-412.

16 Lee VW, Mok KH: Retinal nerve fiber layer measurement by nerve fiber analyzer in normal subjects and patients with glaucoma. Ophthalmology 1999;106:1006-1008.

17 Neubauer AS, Priglinger S, Thiel MJ, Bechmann M, Ulbig MW: Retinal maps: Retinal thickness analyzer (RTA) compared to optical coherence tomography (OCT). IOVS Suppl 2001;42:S793.

18 Hee MR, Izatt JA, Swanson EA, Huang D, Schuman JS, Lin CP, Puliafito CA, Fujimoto JG: Optical coherence tomography of the human retina. Arch Ophthalmol 1995;113:325332.

19 Huang D, Swanson EA, Lin CP, Schuman JS, Stinson WG, Chang W, Hee MR, Flotte T, Gregory K, Puliafito CA, et al: Optical coherence tomography. Science 1991;254:11781181.

20 Emi K, Kobayashi Y, Chujo S, Fujioka C, Yokoyama M: The biometry of each thickness of the human retina, choroid and sclera by using ultrasound and Fourier analysis - at the foveola (in Japanese). Nippon Ganka Gakkai Zasshi 1983;87:74-78.

21 Sanchez-Tocino H, Alvarez-Vidal A, Maldonado MJ, Moreno-Montanes J, Garcia-Layana A: Retinal thickness study with optical coherence tomography in patients with diabetes. Invest Ophthalmol Vis Sci 2002;43:1588-1594.

22 Polito A, Shah SM, Haller JA, Zimmer-Galler I, Zeimer R, Campochiaro PA, Vitale S: Comparison between retinal thickness analyzer and optical coherence tomography for assessment of foveal thickness in eyes with macular disease. Am J Ophthalmol 2002;134:240-251.

23 Neubauer AS, Chryssafis C, Thiel M, Priglinger S, Welge-Lussen U, Kampik A: Screening for diabetic retinopathy and optic disc topography with the 'retinal thickness analyzer' (RTA) (in German). Ophthalmologe 2005; 102:251-258.

24 Miglior S, Albe E, Guareschi M, Rossetti L, Orzalesi N: Intraobserver and interobserver reproducibility in the evaluation of optic disc stereometric parameters by Heidelberg Retina Tomograph. Ophthalmology 2002;109:10721077.

25 Sung VC, Bhan A, Vernon SA: Agreement in assessing optic discs with a digital stereoscopic optic disc camera (Discam) and Heidelberg retina tomograph. Br J Ophthalmol 2002;86: 196-202.
26 Saruhan A, Orgul S, Kocak I, Prunte C, Flammer J: Descriptive information of topographic parameters computed at the optic nerve head with the Heidelberg retina tomograph. J Glaucoma 1998; 7:420-429.

27 Azuara-Blanco A, Spaeth GL, Nicholl J, Lanzl IM, Augsburger JJ: Comparison between laser scanning tomography and computerised image analysis of the optic disc. Br J Ophthalmol 1999;83:295-298.

28 Jonas JB, Mardin CY, Grundler AE: Comparison of measurements of neuroretinal rim area between confocal laser scanning tomography and planimetry of photographs. Br J Ophthalmol 1998;82:362-366.

29 Jonas JB, Gusek GC, Naumann GO: Optic disc, cup and neuroretinal rim size, configuration and correlations in normal eyes. Invest Ophthalmol Vis Sci 1988;29:1151-1158.

30 Mardin CY, Horn FK, Jonas JB, Budde WM: Preperimetric glaucoma diagnosis by confocal scanning laser tomography of the optic disc. $\mathrm{Br}$ J Ophthalmol 1999;83:299-304.

31 Wollstein G, Garway-Heath DF, Hitchings RA: Identification of early glaucoma cases with the scanning laser ophthalmoscope. Ophthalmology 1998;105:1557-1563.

32 Gherghel D, Orgul S, Prunte C, Gugleta K, Lubeck P, Gekkieva M, Flammer J: Interocular differences in optic disc topographic parameters in normal subjects. Curr Eye Res 2000; 20:276-282.

33 Vijaya L, Varma M, Krishna Kumar R, Saraniya AS, Babu G, Subash S, Sukumar B: Retinal nerve fiber layer measurements in Indian eyes using the scanning laser polarimeter, GDx. Indian J Ophthalmol 2004;52:215220.

34 Hermann MM, Theofylaktopoulos I, Bangard N, Jonescu-Cuypers C, Coburger S, Diestelhorst M: Optic nerve head morphometry in healthy adults using confocal laser scanning tomography. Br J Ophthalmol 2004;88:761765.

35 Zeimer R, Asrani S, Zou S, Quigley H, Jampel $\mathrm{H}$ : Quantitative detection of glaucomatous damage at the posterior pole by retinal thickness mapping: a pilot study. Ophthalmology 1998; 105:224-231.

36 Guedes V, Schuman JS, Hertzmark E, Wollstein G, Correnti A, Mancini R, Lederer D, Voskanian S, Velazquez L, Pakter HM, PedutKloizman T, Fujimoto JG, Mattox C: Optical coherence tomography measurement of macular and nerve fiber layer thickness in normal and glaucomatous human eyes. Ophthalmology 2003; 110:177-189.

37 Lederer DE, Schuman JS, Hertzmark E, Heltzer J, Velazques LJ, Fujimoto JG, Mattox C: Analysis of macular volume in normal and glaucomatous eyes using optical coherence tomography. Am J Ophthalmol 2003;135:838843. 